\title{
Reply to Letter to Editor
}

\section{Potent Anticoagulants are Associated with a Higher All-cause Mortality Rate after Hip and Knee Arthroplasty}

\author{
Nigel E. Sharrock BMedSci, MB, ChB, \\ Alejandro Gonzalez Della Valle MD, \\ George Go BS, Stephen Lyman PhD, \\ Eduardo A. Salvati MD
}

Published online: 4 June 2008

(C) The Association of Bone and Joint Surgeons 2008

Reply

Dear Sir:

We thank Doctors Eriksson, Friedman, Cushner, and Lassen for their letter regarding our recently published manuscript: Potent anticoagulants are associated with a higher all-cause mortality rate after hip and knee arthroplasty [15].

They have challenged the evidence presented in our paper which suggests that potent anticoagulants are associated with higher mortality than multimodal thromboprophylaxis by raising numerous issues related to the selection, analysis, and presentation of the data. Unfortunately they did not address the core messages of our paper which were: (1) that pulmonary emboli occur despite the use of potent anticoagulants; and (2) that these agents have never been shown to reduce mortality.

(1) Eriksson et al. challenged our decision of including different potent anticoagulants in Group A, arguing that all anticoagulants are not equivalent. Although anticoagulants may have different mechanisms of action, the all-cause mortality with these different drugs seems similar, none seemed to eliminate

N. E. Sharrock $(\bowtie)$, G. Go

Department of Anesthesiology, Hospital for Special Surgery, 535 East 70th Street, New York, NY 10021, USA

e-mail: sharrockn@hss.edu

A. Gonzalez Della Valle, E. A. Salvati

Department of Orthopaedic Surgery, Hospital for Special

Surgery, New York, NY, USA

S. Lyman

Foster Center for Clinical Outcome Research, Hospital for Special Surgery, New York, NY, USA pulmonary emboli, and they all share the same unwanted bleeding risk. The all-cause mortality in the Group C (patients receiving warfarin alone) was no different than in Group A (patients receiving potent anticoagulants alone). Until someone can show that one of these anticoagulants results in lower allcause mortality than another, one must assume they all carry the same risk.

(2) They questioned the quality and consistency of the data in the different groups: In Groups B (multimodal thromboprophylaxis with preferred use of aspirin) and $\mathrm{C}$, there are some cohort studies, and some using "intention to treat"; whereas the majority of Group A studies (potent anticoagulants) were drug-industry sponsored randomized trials. Eriksson et al. assumed that randomized trials provide more robust data thus explaining the difference in mortality between the groups. However, in the majority of these randomized trials, patients were excluded for various reasons including thrombocytopenia, renal insufficiency, or bilateral surgery. Cohort studies include these patients who are at greater risk of adverse outcomes. The twocohort trial of patients in Group A had an all-cause mortality rate of $0.61 \%$ (16 of 2629) [10,11], whereas the randomized studies had a rate of $0.36 \%$ (44 of 12121). This suggests that the risk of using powerful anticoagulants in the general population may be even greater than suggested from randomized trials.

(3) Eriksson et al. pointed out that we incorrectly cited the study by Lachiewicz et al. [8] as being a prospective cohort rather than a randomized trial. It was indeed a randomized trial of two types of pneumatic compression devices. However, as all patients received multimodal thromboprophylaxis, we thought it more appropriate to designate them as a prospective cohort 
as they were not randomized to the pharmacologic agents being evaluated in our review.

(4) They mentioned that we included two deaths in the so-called "placebo group" from the study by Heit et al. [7]. Their statement is incorrect. In that study, all patients received potent anticoagulation during their hospital stay. At discharge they were randomized to receive a placebo or continue with potent anticoagulation. All patients in the study, including those in the placebo group received potent anticoagulation for 4 to 10 days during their hospital stay.

(5) Eriksson et al. stated that the diagnosis of pulmonary embolism in our study is not based in a central, blinded adjudication of outcome. This is correct. The diagnosis of a pulmonary embolus was adjudicated based on the information in each publication. As we stated in our article [15], one of our major goals was to introduce and use the concept of all-cause mortality that encompasses all benefits and complications of thromboprophylaxis. No central, blinded adjudication of the outcome "death" is needed.

(6) They also stated there is "significant heterogeneity" in mortality rates between the various Group A studies, ranging from $0 \%$ to $0.62 \%$, which invalidates any of our conclusions. The $0 \%$ rate involved the smallest cohorts that included 104, 132, and 643 patients in Group A, and 100 and 200 patients in Group B. Sample size accounts for much of the variance. The other variable is length of followup (6 vs. 12 weeks). In addition, they state that "two of the studies in Group A (potent anticoagulant group) completed enrollment by 1996 and were unlikely to be representative of modern practice". However, Lassen et al. [9] and Geerts et al. [6] cited rates of fatal pulmonary embolism from the 1960s and 1970s [5] to justify the current use of potent anticoagulants ("Some deep-vein thromboses embolize, resulting in a pulmonary embolism that is fatal in $0.1-0.4 \%$ of unprotected patients" [5].)

(7) Of most importance to Eriksson et al. is the argument that our study did not address the compelling arguments for anticoagulant-based thromboprophylaxis set forth by Geerts et al. in the ACCP Guidelines [6]. The majority of the so-called "evidence based" information, is in fact derived from pharmaceutical industry sponsored trials that use DVT on venography as the primary end point. We acknowledge that this is relevant but nevertheless a surrogate end point. The lack of evidence that "pharmacologic thromboprophylaxis" has never been shown to reduce mortality is not addressed in the ACCP Guidelines [6]. Our study suggests that mortality may even be increased with these drugs. A new approach to guidelines for thromboprophylaxis following joint replacement surgery obviously is needed.

The concern of the orthopaedic community $[1-3,12,14]$ has resulted in the AAOS forming a panel of experts. They recently released the AAOS guidelines for prevention of thromboembolism following THA and TKA [13]. They focus on the stratification of patients based on the risks of venous thromboembolism and bleeding. The end points of the guidelines include symptomatic $\mathrm{PE}$ and all-cause mortality. As a consequence of a detailed analysis of the literature, the use of aspirin for pharmacologic prophylaxis is contemplated when patients have a standard venous thromboembolism risk or a high risk of bleeding, and the use of regional anesthesia is encouraged. The guidelines will allow orthopaedic surgeons to use the pharmacologic prophylaxis that they feel more comfortable with, without the need to prescribe potent anticoagulants owing to fear of potential litigation.

Our study has limitations that were discussed extensively in the manuscript. Still, based on the available information it seems reasonable to believe that the use of potent anticoagulation may increase all-cause mortality regardless of the beneficial effect in the rate of DVT.

Finally, we have no conflict of interest to declare. None of us have received funding from pharmaceutical companies relating to thromboembolic disease, consulting fees from pharmaceutical companies, nor testified as expert witnesses in cases related to venous thromboembolism [4].

\section{References}

1. Burnett RS, Clohisy JC, Wright RW, McDonald DJ, Shively RA, Givens SA, Barrack RL. Failure of the American College of Chest Physicians-1A protocol for lovenox in clinical outcomes for thromboembolic prophylaxis. J Arthroplasty. 2007;22:317324.

2. Butt AJ, McCarthy T, Kelly IP, Glynn T, McCoy G. Sciatic nerve palsy secondary to postoperative haematoma in primary total hip replacement. J Bone Joint Surg Br. 2005;87:1465-1467.

3. Callaghan JJ, Dorr LD, Engh GA, Hanssen AD, Healy WL, Lachiewicz PF, Lonner JH, Lotke PA, Ranawat CS, Ritter MA, Salvati EA, Sculco TP, Thornhill TS. Prophylaxis for thromboembolic disease: recommendations from the American College of Chest Physicians-are they appropriate for orthopaedic surgery? J Arthroplasty. 2005;20:273-274.

4. Choudhry NK, Stelfox HT, Detsky AS. Relationships between authors of clinical practice guidelines and the pharmaceutical industry. JAMA. 2002;287:612-617.

5. Coventry MB, Beckenbaugh RD, Nolan DR, Ilstrup DM. 2,012 total hip arthroplasties: a study of postoperative course and early complications. J Bone Joint Surg Am. 1974;56:273-284.

6. Geerts WH, Pineo GF, Heit JA, Bergqvist D, Lassen MR, Colwell CW, Ray JG. Prevention of venous thromboembolism: the Seventh ACCP Conference on Antithrombotic and Thrombolytic Therapy. Chest. 2004;126(3 suppl):338S-400S.

7. Heit JA, Elliott CG, Trowbridge AA, Morrey BF, Gent M, Hirsh J. Ardeparin sodium for extended out-of-hospital prophylaxis 
against venous thromboembolism after total hip or knee replacement: a randomized, double-blind, placebo-controlled trial. Ann Intern Med. 2000;132:853-861.

8. Lachiewicz PF, Kelley SS, Haden LR. Two mechanical devices for prophylaxis of thromboembolism after total knee arthroplasty: a prospective, randomised study. J Bone Joint Surg Br. 2004; 86:1137-1141.

9. Lassen MR, Bauer KA, Eriksson BI, Turpie AG. European Pentasaccharide Elective Surgery Study. Postoperative fondaparinux versus preoperative enoxaparin for prevention of venous thromboembolism in elective hip-replacement surgery: a randomised double-blind comparison. Lancet. 2002;359:1715-1720.

10. Leclerc JR, Gent M, Hirsh J, Geerts WH, Ginsberg JS. The incidence of symptomatic venous thromboembolism during and after prophylaxis with enoxaparin: a multi-institutional cohort study of patients who underwent hip or knee arthroplasty. Canadian Collaborative Group. Arch Intern Med. 1998;158:873-878.

11. Lindahl TL, Lundahl TH, Nilsson L, Andersson CA. APCresistance is a risk factor for postoperative thromboembolism in elective replacement of the hip or knee: a prospective study. Thromb Haemost. 1999;81:18-21.

12. Patel VP, Walsh M, Sehgal B, Preston C, DeWal H, Di Cesare PE. Factors associated with prolonged wound drainage after primary total hip and knee arthroplasty. J Bone Joint Surg Am. 2007;89:33-38.

13. Prevention of symptomatic pulmonary embolism in patients undergoing total hip or knee arthroplasty. American Academy of Orthopaedic Surgeons. 2007 http://www.aaos.org/Research/guide lines/PE_guideline.pdf. Accessed 28 May 2008.

14. Sachs RA, Smith JH, Kuney M, Paxton L. Does anticoagulation do more harm than good?: A comparison of patients treated without prophylaxis and patients treated with low-dose warfarin after total knee arthroplasty. J Arthroplasty. 2003;18: 389-395.

15. Sharrock NE, Gonzalez Della Valle A, Go G, Lyman S, Salvati EA. Potent anticoagulants are associated with a higher all-cause mortality rate after hip and knee arthroplasty. Clin Orthop Relat Res. 2008;466:714-721. 